\title{
Study on Forecasting Method of Forest Fire Risk Grade in Putian City, China
}

\author{
Gefu Zhuang \\ Xianyou County Meteorological Bureau of Fujian Province, Xianyou, China \\ Email: zgf810801@126.com
}

How to cite this paper: Zhuang, G. F. (2019). Study on Forecasting Method of Forest Fire Risk Grade in Putian City, China. Journal of Geoscience and Environment Protection, 7, 198-205. https://doi.org/10.4236/gep.2019.712014

Received: October 11, 2019

Accepted: December 27, 2019

Published: December 30, 2019

Copyright $\odot 2019$ by author(s) and Scientific Research Publishing Inc. This work is licensed under the Creative Commons Attribution International License (CC BY 4.0).

http://creativecommons.org/licenses/by/4.0/

\section{(c) (i) Open Access}

\begin{abstract}
From January 1, 2014, the basic stations of meteorological observation countries have changed from small evaporation observations to large-scale evaporation observations. National general weather stations have canceled observations on evaporation, but small evaporation is very important for forest fire risk prediction. In order to make the prediction of forest fire risk level objectively, weather data in Putian City, China and the multi-linear regression analysis method is used to calculate the daily evaporation amount in the more advanced SPSS16.0 software (English version), and the data of the last 5 years of each site are selected and fitted. Results showed that we accurately calculated the evaporation of the next day to make up for the lack of data due to the adjustment of the evaporation observation project. According to the forest fire risk weather index corresponding to many meteorological factors such as evaporation, temperature, humidity, sunshine and wind speed, the forest fire risk meteorological grade standard was designed to make a more accurate forest fire risk grade forecast.
\end{abstract}

\section{Keywords}

Evaporation, Weather Index, Forest Fire Risk, Rating

\section{Introduction}

Forest fire insurance is closely related to many meteorological factors. According to literature research (Millán et al., 1998; Holsten et al., 2013; Qu \& Hu, 2008), meteorological elements that have a greater impact on forest fire risk grades have daily evaporation, daily maximum temperature, poor temperature, minimum daily (14 hours) relative humidity, and maximum daily. Wind speed, daily average wind speed, and the number of days without rain in the previous period. However, since January 1, 2014, the national base station has been changed from 
the original small-scale evaporation observation to the large-scale evaporation observation. The national general station has canceled the observation of the evaporation amount, but the daily evaporation amount is extremely important for the forest fire risk level prediction (Takle et al., 1994; Liu et al., 2002; Vacchiano et al., 2013). To objectively make the forecast of the forest fire risk level the next day, we must first accurately calculate the evaporation of the next day to compensate for the lack of data due to the adjustment of the evaporation observation project. Therefore, this paper intends to use the relevant meteorological factors to explore the weight relationship between daily evaporation and temperature, humidity, sunshine and wind speed to establish a linear equation for back calculating the daily evaporation, and then through the daily evaporation, temperature, humidity, sunshine and The wind speed and other meteorological factors are fitted, and the next day's forest fire risk weather index is calculated, so that the next day forest fire risk grade forecast is produced according to the judgment standard.

Based on the evaporation algorithm and combining various meteorological elements or variables closely related to forest fire risk, this paper designs the forecast method of forest fire risk meteorological grades in all counties and districts of Putian City, and uses Microsoft Visual Basic (VB.net) as the main programming language to produce daily forecasting work modules. When the next day's forecast is rain-free (including local light rain or sporadic light rain), open the platform to input the corresponding data, the system will automatically calculate, correct and display the next day forest fire risk rating. If forest fire risk level is greater than or equal to 3 , the system can beautomatic running based on the template. Form a relatively standardized, editable word document (forest fire risk rating service products), in order to be timely sent to the party and government leading organs and forestry departments to maximize the prevention of forest fires.

\section{Data and Methods}

Firstly, the multivariate linear regression analysis is used to calculate the correlation coefficient between the daily maximum temperature, the 14-hour relative humidity, the sunshine hours, the daily average wind speed, the daily maximum wind speed, and the temperature difference. The source of the data used in this study was the local meteorological department in Putian City, China. Then establish a multivariate one-time regression equation $[\mathrm{f}(\mathrm{x})]$ to calculate the evaporation amount of the day; secondly, collect the specific algorithm of the forest fire risk meteorological grade in Putian City, and use VB.net (Tatiana et al., 2018; Fuat et al., 2005) as the main programming language to collect the above algorithms into the setting. On the set modules, a systematic human-computer interaction interface production platform can be formed. Finally, we put the system into business trial operation. We compared the results of the operation with the original platform objectively and found that the problems were resolved in time. In this way, the system functions can be continuously improved and op- 
timized, allowing it to achieve automatic and objective forecasting of the system. After acceptance, the system can be formally put into daily weather forecast service for forest fire danger in Putian City and its counties and districts' weather bureaus.

\section{Results}

\subsection{Calculation of Evaporation}

We first calculated the evaporation of Xianyou County. Information on the daily evaporation, daily maximum temperature, 14-hour relative humidity, sunshine hours, daily maximum wind speed, daily average wind speed and temperature difference of a small evaporator with a diameter of $20 \mathrm{~cm}$ in the last five years of Xianyou Station from 2009 to 2013 According to the multiple linear regression analysis method in SPSS16.0 software (English version), the correlation coefficient $\mathrm{R}$ between the daily evaporation amount and each element is obtained, as shown in Table 1.

Next, we calculated the evaporation of Putian Station. The daily evaporation, daily maximum temperature, 14-hour relative humidity, sunshine hours, daily maximum wind speed, daily average wind speed, and temperature difference of a small evaporator with a diameter of $20 \mathrm{~cm}$ in the last five years of Putian Station in 2009-2013, According to the multiple linear regression analysis method in SPSS16.0 software (English version), the correlation coefficient R between the daily evaporation amount and each element is obtained, as shown in Table 2.

We also performed the calculation of the average evaporation of the two stations. The daily evaporation, daily maximum temperature, 14-hour relative humidity, sunshine hours, daily maximum wind speed, daily average wind speed and temperature of a small evaporator with a diameter of $20 \mathrm{~cm}$ in the last five years of Xianyou Station and Putian Station from 2009 to 2013 The difference average data is used to determine the correlation coefficient $\mathrm{R}$ between the daily evaporation amount and each element according to the multiple linear regression analysis method in SPSS16.0 software (English version). See Table 3 for details.

The above three kinds of data were fitted and compared. The evaporation calculated by the data of Putian Station is the closest to the actual situation, that is, the fitting rate is the highest. Therefore, the data of Putian Station is used to represent the calculation formula of daily evaporation in Putian City,

$$
E=\left(27.78+0.209 \times T_{\max }-0.633 \times R_{h 14}+0.32 \times S_{h}+0.575 \times W-0.217 \times \delta T\right) / 10,
$$

Table 1. Correlation coefficient between daily evaporation and various elements of Xianyou Station.

\begin{tabular}{cccccc}
\hline & $\begin{array}{c}\text { Daily maximum } \\
\text { temperature }\end{array}$ & $\begin{array}{c}\text { Relative humidity } \\
\text { at 14 o'clock }\end{array}$ & $\begin{array}{c}\text { Sunshine } \\
\text { hours }\end{array}$ & $\begin{array}{c}\text { Daily average } \\
\text { wind speed }\end{array}$ & $\begin{array}{c}\text { Daily temperature } \\
\text { difference }\end{array}$ \\
\hline $\begin{array}{c}\text { Daily } \\
\text { evaporation }\end{array}$ & 0.736 & -0.680 & 0.830 & 0.320 & 0.581 \\
\hline
\end{tabular}


Table 2. Correlation coefficient between daily evaporation and various elements of $\mathrm{Pu}$ tian Station.

\begin{tabular}{cccccc}
\hline & $\begin{array}{c}\text { Daily maximum } \\
\text { temperature }\end{array}$ & $\begin{array}{c}\text { Relative humidity } \\
\text { at 14 o'clock }\end{array}$ & $\begin{array}{c}\text { Sunshine } \\
\text { hours }\end{array}$ & $\begin{array}{c}\text { Daily average } \\
\text { wind speed }\end{array}$ & $\begin{array}{c}\text { Daily temperature } \\
\text { difference }\end{array}$ \\
\hline $\begin{array}{c}\text { Daily } \\
\text { evaporation }\end{array}$ & 0.672 & -0.622 & 0.821 & 0.386 & 0.468 \\
\hline
\end{tabular}

Table 3. Correlation coefficient between the average daily evaporation and each element of the two stations.

\begin{tabular}{cccccc}
\hline & $\begin{array}{c}\text { Daily maximum } \\
\text { temperature }\end{array}$ & $\begin{array}{c}\text { Relative humidity } \\
\text { at } 14 \text { o'clock }\end{array}$ & $\begin{array}{c}\text { Sunshine } \\
\text { hours }\end{array}$ & $\begin{array}{c}\text { Daily average } \\
\text { wind speed }\end{array}$ & $\begin{array}{c}\text { Daily temperature } \\
\text { difference }\end{array}$ \\
\hline $\begin{array}{c}\text { Daily } \\
\text { evaporation }\end{array}$ & 0.698 & -0.626 & 0.824 & 0.352 & 0.488 \\
\hline
\end{tabular}

where, $E$ is daily evaporation, $T_{\max }$ is daily maximum temperature, $R_{h 14}$ is relative humidity at 14 o'clock, $S_{h}$ is sunshine hours in the whole day, $W$ is daily average wind speed, and $\delta T$ is daily temperature difference. What we need to pay attention to is that among them daily maximum temperature, sunshine hours, daily average wind speed, and daily temperature difference are all expanded by 10 times (integer) input. For example, if the daily maximum temperature is $32.5^{\circ} \mathrm{C}$, 325 should be input, and the rest are analogous. Relative humidity at 14 o'clock is directly input, such as, $68 \%$ input 68 .

\subsection{Forest Fire Risk Rating}

We first divided the forest fire risk rating, and the forest fire danger meteorological grade was classified into five levels according to the degree of danger and the degree of combustion as no fire risk, low fire risk, moderate fire risk, high fire risk and extremely high fire risk. The lowest level is level 1 , and the highest level is level 5. The specific division is shown in Table 4.

Then, we give the formula for calculating the total forest fire risk weather index as follows,

$$
H T Z=A+B+C+D+E,
$$

where, $A$ is the forest fire risk weather index based on the highest temperature (Table 5), $B$ is the forest fire risk weather index based on the minimum (14 o'clock) relative humidity (Table 6), and $C$ is the forest fire risk weather index based on the number of consecutive no precipitation days after the precipitation day (Table 7), $D$ is the forest fire risk weather index based on the maximum wind power (Table 8), and $\mathrm{E}$ is the forest fire risk weather index based on the small amount of evaporation the next day (Table 9).

Finally, we also need to correct the fire risk rating. Farmers burning straw and ritual fires such as the Ching Ming Festival and the winter solstice may cause forest fires. The above-mentioned human factors should also be considered, and we give an additional level of correction. For example, in the period from February to March and September to October of each year, when the forest fire risk 
Table 4. Forest fire risk rating specific division.

\begin{tabular}{ccccc}
\hline Forest fire risk & Danger level & Flammability & Spread degree & HTZ \\
\hline 1 & None & None & None & $\leq 29$ \\
2 & Low & Hard & Hard & $30-49$ \\
3 & Moderate & Flammable & Spreadable & $50-69$ \\
4 & High & Easy & Easy & $70-89$ \\
5 & Extreme & Extreme & Extreme & $\geq 90$ \\
\hline
\end{tabular}

Notes: HTZ is total forest fire risk weather index.

Table 5. The forest fire risk weather index based on the highest temperature.

\begin{tabular}{cc}
\hline Highest temperature $\left({ }^{\circ} \mathrm{C}\right)$ & Forest fire risk weather index \\
\hline$\leq 5.0$ & 0 \\
$5.1-15.0$ & 2 \\
$15.1-20.0$ & 4 \\
$20.1-25.0$ & 8 \\
$25.1-30.0$ & 12 \\
$30.1-35.0$ & 16 \\
$\geq 35$. & 20 \\
\hline
\end{tabular}

Table 6. The forest fire risk weather index based on the minimum (14 o'clock) relative humidity.

\begin{tabular}{cc}
\hline Minimum (14 o'clock) relative humidity (\%) & Forest fire risk weather index \\
\hline$\geq 90$ & 0 \\
$80-89$ & 1 \\
$70-79$ & 2 \\
$60-69$ & 4 \\
$50-59$ & 8 \\
$40-49$ & 12 \\
$30-39$ & 16 \\
$\leq 29$ & 20 \\
\hline
\end{tabular}

Table 7. The forest fire risk weather index based on the number of consecutive no precipitation days after the precipitation day.

\begin{tabular}{ccccccccc}
\hline \multirow{2}{*}{$\begin{array}{c}\text { Recent } \\
\text { precipitation }(\mathrm{mm})\end{array}$} & \multicolumn{7}{c}{ The forest fire risk weather index } \\
\cline { 2 - 8 } & 1 day & 2 days & 3 days & 4 days & 5 days & 6 days & 7 days & $\geq 8$ days \\
\hline $0.3-2.0$ & 5 & 10 & 15 & 20 & 25 & 30 & 35 & 40 \\
$2.1-5.0$ & 0 & 5 & 10 & 15 & 20 & 25 & 30 & 35 \\
$5.1-10.0$ & 0 & 0 & 5 & 10 & 15 & 20 & 25 & 30 \\
$\geq 10.1$ & 0 & 0 & 0 & 5 & 10 & 15 & 20 & 25 \\
\hline
\end{tabular}

Notes: The precipitation is less than $0.3 \mathrm{~mm}$ as no precipitation calculation. 
Table 8. The forest fire risk weather index based on the maximum wind power.

\begin{tabular}{ccc}
\hline Wind power level & Wind speed $(\mathrm{m} / \mathrm{s})$ & The forest fire risk weather index \\
\hline 0 & $0.0-0.2$ & 0 \\
1 & $0.3-1.5$ & 2 \\
2 & $1.6-3.3$ & 4 \\
3 & $3.4-5.4$ & 6 \\
4 & $5.5-7.9$ & 8 \\
5 & $8.0-10.7$ & 10 \\
6 & $10.8-13.8$ & 12 \\
7 & $13.9-17.1$ & 14 \\
$\geq 8$ & $17.2-20.7$ & 16 \\
\hline
\end{tabular}

Table 9. The forest fire risk weather index based on the small amount of evaporation the next day.

\begin{tabular}{cc}
\hline Next day evaporation $(\mathrm{mm})$ & The forest fire risk weather index \\
\hline 0.0 & 0 \\
$0.1-1.9$ & 2 \\
$2.0-3.9$ & 5 \\
$4.0-5.9$ & 10 \\
$6.0-7.9$ & 15 \\
$8.0-9.9$ & 20 \\
$\geq 10.0$ & 25 \\
\hline
\end{tabular}

rating is less than or equal to 4 , we should added by one level to make a revised forecast. In addition, during the Ching Ming Festival and the winter solstice, the people sacrificed and burned fire. Since the specific date has not been determined, when the forest fire risk rating is less than or equal to level 4 , it should be manually increased by one level.

\subsection{Forecast Service Documentation and Platform}

When the next day's forecast has no precipitation (including local precipitation or sporadic precipitation), the forest fire risk level $\geq 3$, the system will automatically generate a word document. The forecast service contents of each level are as follows: When the forest fire risk is level 3 , it is expected that the weather in this city (county, district) will be dryer from today to tomorrow tomorrow, and the forest fire risk meteorological level will reach three levels, which is more likely to cause forest fires, etc. Do a good job in forest fire prevention. When the forest fire insurance is level 4, it is expected that the weather in this city (county, district) will be very dry from today to tomorrow. The weather level of forest fire danger will reach four levels, which is easy to cause forest and other fires. Please do forest fire prevention work. When the forest fire risk is 5 , it is expected that the weather in the city (county, district) will be extremely dry from today to tomorrow. The weather level of forest fire danger will reach five grades, which is 
very likely to cause forest and other fires. Please do forest fire prevention work.

In order to achieve the specific application of the forest fire risk meteorological grade, the specific application, the forest fire danger meteorological grade, the formation of the corresponding forecast service product, the project development supporting platform, the technical support for the meteorological service personnel, and the decision meteorological service for the purpose of disaster prevention and reduction Provide more data support.

In response to the above requirements, the platform functions were analyzed in detail, and the requirements for the interface and the setting of the window were unified, and the preliminary design ideas were gradually completed. Under the premise of stable and accurate operation of the platform, in order to enable the operator to use the platform easily and conveniently, the research group is committed to simplifying the system configuration and operation of the platform and simplifying the interface. The platform has been extensively tested, modified, and repeatedly validated to continuously improve its stability, accuracy, and operability.

The daily maximum temperature, the daily minimum relative humidity, the previous precipitation and the number of consecutive sunny days, the wind, the temperature difference, the sunshine hours, etc. are input, and the corresponding daily evaporation amount and the forest fire risk weather index value of each element are automatically calculated. Click on "Fire Insurance Forecast" to automatically calculate the forest fire risk rating. When the forest fire risk level reaches the third level, the warning icon is displayed. After selecting the corresponding template and drafting, proofreading, reviewing, issuing, transmitting and other relevant information on the right side of the platform, click "Generate Document", the platform can form the corresponding forest fire risk rating according to the template service product.

\section{Conclusion and Discussion}

In this paper, the multi-linear regression analysis method is used to calculate the daily evaporation amount in the more advanced SPSS16.0 software (Fan et al., 2017; Yu et al., 2017), and the data of the last 5 years of each site are selected and fitted. After repeated comparison and verification, the closest linearity to the reality is established. The regression equation makes the predicted evaporation amount basically consistent with the annual historical data.

Compared with the perennial, this paper adds weather factors such as daily maximum wind speed, daily average wind speed, daily maximum temperature, and recent precipitation level, which are closely related to evaporation, making the forest fire risk rating more accurate.

\section{Conflicts of Interest}

The author declares no conflicts of interest regarding the publication of this paper. 


\section{References}

Fan, J. B., Ma, J., Xia N., Sun L., \& Liu, H. J. (2017). Clinical Value of Combined Detection of CK-MB, MYO, cTnL and Plasma NT-proBNP in Diagnosis of Acute Myocardial Infarction. Clinical Laboratory, 63, 427.

https://doi.org/10.7754/Clin.Lab.2016.160533

Fuat, Y., Vural, Y., \& Ahmet, S. (2005). Winclastour-A Visual Basic Program for Tourmaline Formula Calculation and Classification. Computers \& Geosciences, 32, 11561168. https://doi.org/10.1016/j.cageo.2005.10.021

Holsten, A., Anto, R. D., Luís, C., \& Kropp, J. P. (2013). Evaluation of the Performance of Meteorological Forest Fire Indices for German Federal States. Forest Ecology \& Management, 287, 123-131. https://doi.org/10.1016/j.foreco.2012.08.035

Liu, C. M., Zhang, X. Y., \& Zhang, Y. Q. (2002). Determination of Daily Evaporation and Evapotranspiration of Winter Wheat and Maize by Large-Scale Weighing Lysimeter and Micro-Lysimeter. Journal of Hydraulic Engineering, 111, 109-120. https://doi.org/10.1016/S0168-1923(02)00015-1

Millán, M., María, J., \& Badenas, C. (1998). Meteorological Processes Relevant to Forest Fire Dynamics on the Spanishmediterranean Coast. Journal of Applied Meteorology, 37, 83-100. https://doi.org/10.1175/1520-0450(1998)037<0083:MPRTFF>2.0.CO;2

Qu, Z. L., \& Hu, H. Q. (2008). A Prediction Model for Forest Fire-Burnt Area Based on Meteorological Factors. Chinese Journal of Applied Ecology, 18, 2705-2709.

Takle, E. S., Bramer, D. J., Heilman, W. E., Thompson, M. R., Takle, E. S., \& Brame, D. J. (1994). A Synoptic Climatology for Forest-Fires in the NE US and Future Implications from GCM Simulations. International Journal of Wildland Fire, 4, 217-224. https://doi.org/10.1071/WF9940217

Tatiana, S. S., Dorogokupets, P. I., Konstantin, D., Litasov, B., Danilov, D., \& Anna, M. D. (2018). Spreadsheets to Calculate p-v-t Relations, Thermodynamic and Thermoelastic Properties of Silicates in the Mgsio 3-Mgo System. High Pressure Research, 9, 1-19.

Vacchiano, G., Stanchi, S., Marinari, G., Ascoli, D., Zanini, E., \& Motta, R. (2013) Fire Severity, Residuals and Soil Legacies Affect Regeneration of Scots Pine in the Southern Alps. Science of the Total Environment, 472, 778-788.

https://doi.org/10.1016/j.scitotenv.2013.11.101

Yu, Y. X., Xu, S., You, H., Zhang, Y. J., \& Wu, J. B. (2017). In Vivo Synergistic Anti-Tumor Effect of Paclitaxel Nanoparticles Combined with Radiotherapy on Human Cervical Carcinoma. Drug Delivery, 24, 75-82.

https://doi.org/10.1080/10717544.2016.1230902 